\title{
Sheet metal material resources management in internal supply chains of engineering enterprise
}

\author{
Artyom Smirnov \\ Graduate School of Management and \\ Business \\ Peter the Great St. Petersburg \\ Polytechnic University \\ St. Petersburg, Russia \\ smirnov.artem.a@yandex.ru
}

\author{
Vladimir Kobzev \\ Graduate School of Management and \\ Business \\ Peter the Great St. Petersburg \\ Polytechnic University \\ St. Petersburg, Russia \\ kobzev_vv@mail.ru
}

\author{
Stanislav Skvortsov \\ Graduate School of Management and \\ Business \\ Peter the Great St. Petersburg \\ Polytechnic University \\ St. Petersburg, Russia \\ skvorstas@gmail.com
}

\begin{abstract}
Improving the economic efficiency of industrial enterprises and ensuring their sustainable development depend, in particular, on the using of material resources management tools (MR) based on the principles of lean production using information technology. At the same time, the research of internal supply chains at enterprise allows identifying the main participants in the process, the material and information flows between them, determining the necessary change in the supply chain during the development of allocation innovations taking into account trends of digital economy. At the engineering enterprises, the managers face the task of increasing a sheet metal utilization rate in order to reduce unit technological costs, optimize the cost structure and increase net income. The relevance of this issue is confirmed by the theoretical and practical works of researchers in the field of cutting and packaging tasks, as well as in terms of the environmental problems which are because of increasing production and consumption waste. The purpose of the research is to develop tools of material resources management in lean production for sheet metal cutting at engineering enterprises with single or serial types of production. The tools are also based on the using of information technologies in economic system of an enterprise. At the previous stages of the research a situational analysis of sheet metal cutting and sheet metal material resources management at engineering enterprises was conducted, the main provisions of the sorting method of sheet metal MR after cutting were defined, approbation of certain aspects of the method was carried out using sheet metal cutting cards. The aspects related to micro logistical processes at an enterprise are specified in this article. Further research tasks are also identified.
\end{abstract}

Keywords-digital economy, engineering enterprise, lean production, sheet metal cutting, material utilization rate, business material resources, sorting method

\section{INTRODUCTION}

At engineering enterprises, within the framework of blank production the sheet metal material resources management includes many processes related to micrologistics. Particularly, in organizing sheet metal cutting technologists and managers have the task of increasing the sheet metal utilization rate in order to reduce technological costs, optimize the cost structure, and increase net income. This task includes many subtasks of lean production (in terms of eliminating losses arising in product value creation streams) and micrologistics (management of material and information flows within the enterprise for optimizing them) taking into account development trends of digital economy.
For solving such problems it is required to develop the modern toolkit of material resources management at an engineering enterprise, which will provide managers necessary operational information for timely making management decisions. The aspects confirm the relevance of the study.

In this study it was detected, that in scientific and practical literature about the organization of cutting sheet metal the issue of justified sorting of sheet metal material resources (MR) after cutting into business and non-business ones at engineering enterprises and features of the reflection of information flows about business and non-business MR flows between warehouse and blank production were not fully detailed. Prompt and reasonable sorting of sheet metal after cutting, the results of which are reflected in the information system of enterprise in a certain form, will allow to reduce the costs of storing and transporting non-business material resources from which products will not be produced, to increase the sheet metal utilization rate, to reduce unit sheet metal costs, to optimize the structure of technological costs in manufacturing products from business MR. [1,2] The solution of this problem differs at engineering enterprises with a single or serial production type, because the nomenclature and completeness of blanks and sheet metal material resources after cutting are changed more often than in mass production.

Also the relevance of development of the tools aimed at improving the sheet metal utilization rate is confirmed from the point of environmental problem view [3,4]. When using the rational cutting methods of sheet metal and using business MR in the following technological processes, the load on the infrastructure of processing industrial sheet metal waste is reduced. Thus, the enterprise takes into account the need for the rational use of natural resources and seeks to reduce the environmental impact when organizing its activities.

The object of the research is engineering enterprises with single and serial types of production. The subject of the research is the managerial relations arising in the material resources management in the process of functioning and developing lean production at engineering enterprises.

The purpose of the research is to develop tools of material resources management in lean production for sheet metal cutting at engineering enterprises with single or serial types of production. 
In previous works [5] a situational analysis of sheet metal cutting and sheet metal material resources management at engineering enterprises in Vologda were performed, the main provisions of the method for sorting sheet metal MR after cutting were determined, some aspects of the method were tested on the example of sheet metal cutting cards, the relevance of developing a decision support system (DSS) for sorting was determined and recommendations for using the proposals within enterprise resource planning (ERP) system were partially formulated. In this article the sheet metal cutting process are considered from the point of micrologistical view.

\section{MATERIALS AND METHODS}

The theoretical basis of the study are the works of researchers on the issues of lean production, material resources management and rational cutting of sheet metal. At this stage of the research, it has been revealed that rational cutting of sheet metal is carried out using rational cutting methods, which have been widely studied by researchers: L. V. Kantorovich, V. A. Zalgaller, E. A. Mukhacheva, I. V. Romanovsky, V. M. Kartak, Yu. G. Stoyan and others. The special group ESICUP (Euro Special Interest Group on Cutting and Packing) and a scientific school in Ufa work on the questions of rational cutting. It should also be noted that the study of these problems has led to the solution of problems of logistics transport companies, where the task of the most optimal location of goods in a given twodimensional or three-dimensional space is constantly solved. In $1990 \mathrm{H}$. Dyckhoff proposed a classification of cutting and packaging tasks, which was developed by G. Wascher, H. Haubner, H. Schumann. Thus, domestic and foreign researchers developed mathematical methods and approaches to organizing the rational cutting of industrial materials from the point of view of optimal location of blanks on a given material resource and optimal choice of a material resource for producing blanks from it. [6-10]

The empirical base of the work consists of production processes at engineering enterprises, analytical materials presented in the studied literature.

As methodological basis of the research was selected the concept of lean production, which is focused on a continuous stream of value creation for the consumer, the continuous improvement of the organization's processes through the involvement of staff and elimination of all losses types. As part of the work, the issues of lean production are considered, associated with decreasing unit sheet metal costs due to using business MR, optimization of costs for storage and transportation of business or non-business MR, reduction of time costs for search and transportation of business sheet metal MR in production process.

Also highlighted issues of lean production are related to the concept of supply chain management. In the work, micrologistic processes are considered between participants of the supply chain (warehouse, blank production, technologists, management accounting and specialists) which interact in material and information flows (sheet metal from supplier, business and non-business sheet metal MR, management accounting the values of indicators characterizing business and non-business MR in information system of enterprise). At the same time, some components of supply chain management are considered as the part of the tools of sheet metal MR management (for example, demand forecasting, inventory management of sheet metal, visualization of information about sheet metal residues taking into account classes of business and non-business MR).

It should be noted that the research objective is related to management accounting. The management accounting is aimed at providing managers with operative and reliable information for making timely decisions that affect parameters of operating cycle of manufacturingtechnological system (MTS), gaining competitive advantages in market, net income and business value. Therefore, the theory and practice of management accounting of material costs are studied in the research for determining the specifics of sheet metal accounting during the mastering of lean production and supply chain management at engineering enterprise. [11-15]

The identified research questions are considered taking into account development trends of digital economy in connection with certain requirements for the accumulation, systematization, storage, use and speed of processing management information, and because enterprise specialists work in the relevant information systems. Therefore, the questions of combining the developed proposals with ERP system are studied and the requirements for development of DSS for sorting sheet material resources after cutting are formed in order to take into account the peculiarities of using information technology and software implementation of the research results.

General scientific research methods were used: analysis; synthesis; formalization.

\section{RESULTS}

During the study, it was proposed to organize sheet metal cutting taking into account the developed sorting method of sheet metal MR obtained after cutting. A DSS for sorting sheet metal is being developed together with colleagues in the field of information technology based on the proposed sorting method.

For a more detailed study the sheet metal cutting process is considered from the point of supply chain management view. The main participants in the process are MR warehouse, blank section of the MTS, technologist and management accounting specialist. Material flows: original sheet metal, business and non-business MR. Information flows: production program, design and technological documentation, values of indicators characterizing the original sheet metal and MR of sheet metal obtained after cutting, information on the nomenclature and amount of MR at warehouse.

Based on the program of production the designer designs products and develop design documentation (DD). Based on the DD and information about initial and business sheet metal material resources the technologist develops cutting cards using rational cutting software. At blank section of the MTS sheet metal cutting is made on the basis of cutting cards and received corresponding MR from a warehouse, reasonable sorting of sheet metal MR after cutting into business and non-business is done based on the recommendations of the DSS, business MR are marked and transferred to a warehouse or non-business MR are sold. 
Then business MR are stored and accounted at the warehouse. At the appropriate stage, the participants interact with the ERP system and the DSS for sorting. The card of sheet metal cutting at blank section is represented in table 1 .

TABLE I. CARD OF THE SHEET METAL RATIONAL CUTTING TAKING

\begin{tabular}{|c|c|c|}
\hline $\begin{array}{c}\text { № } \\
\text { categor } \\
\mathbf{y}\end{array}$ & Category & Description \\
\hline 1 & $\begin{array}{l}\text { The purpose of the } \\
\text { process }\end{array}$ & $\begin{array}{l}\text { Rational cutting of sheet metal taking } \\
\text { into account business MR }\end{array}$ \\
\hline 2 & Process owner & Management accounting specialist \\
\hline \multirow[b]{2}{*}{3} & \multirow[b]{2}{*}{ Process boundary } & Start: production program \\
\hline & & $\begin{array}{l}\text { End: production of blanks, business } \\
\text { and non-business sheet metal MR }\end{array}$ \\
\hline \multirow{5}{*}{4} & Process inputs & Providers \\
\hline & $\begin{array}{l}\text { Production } \\
\text { program }\end{array}$ & Management accounting specialist \\
\hline & $\begin{array}{l}\text { Design and } \\
\text { technological } \\
\text { documentation }\end{array}$ & $\begin{array}{l}\text { Specialists of design and technological } \\
\text { department }\end{array}$ \\
\hline & $\begin{array}{l}\text { Data for the DSS } \\
\text { for sorting }\end{array}$ & $\begin{array}{l}\text { Specialists working in the accounting } \\
\text { system, DSS }\end{array}$ \\
\hline & $\begin{array}{l}\text { Management } \\
\text { accounting guide }\end{array}$ & Management accounting specialist \\
\hline & Process outputs & Consumers \\
\hline 5 & $\begin{array}{l}\text { Blanks, business } \\
\text { and non- business } \\
\text { sheet metal MR, } \\
\text { relevant data for } \\
\text { ERP system }\end{array}$ & $\begin{array}{l}\text { Management accounting department, } \\
\text { design and technological department, } \\
\text { subsequent production sections }\end{array}$ \\
\hline 6 & Process limitations & $\begin{array}{l}\text { QMS documents, management orders, } \\
\text { Management accounting guide }\end{array}$ \\
\hline 7 & Resources & $\begin{array}{l}\text { sheet metal MR, personnel, premises, } \\
\text { office equipment, software for rational } \\
\text { cutting, DSS for sorting, sheet metal } \\
\text { MR after cutting, ERP system }\end{array}$ \\
\hline
\end{tabular}

The graphical interpretation of the process is pictured using the UML method in the figure 1.

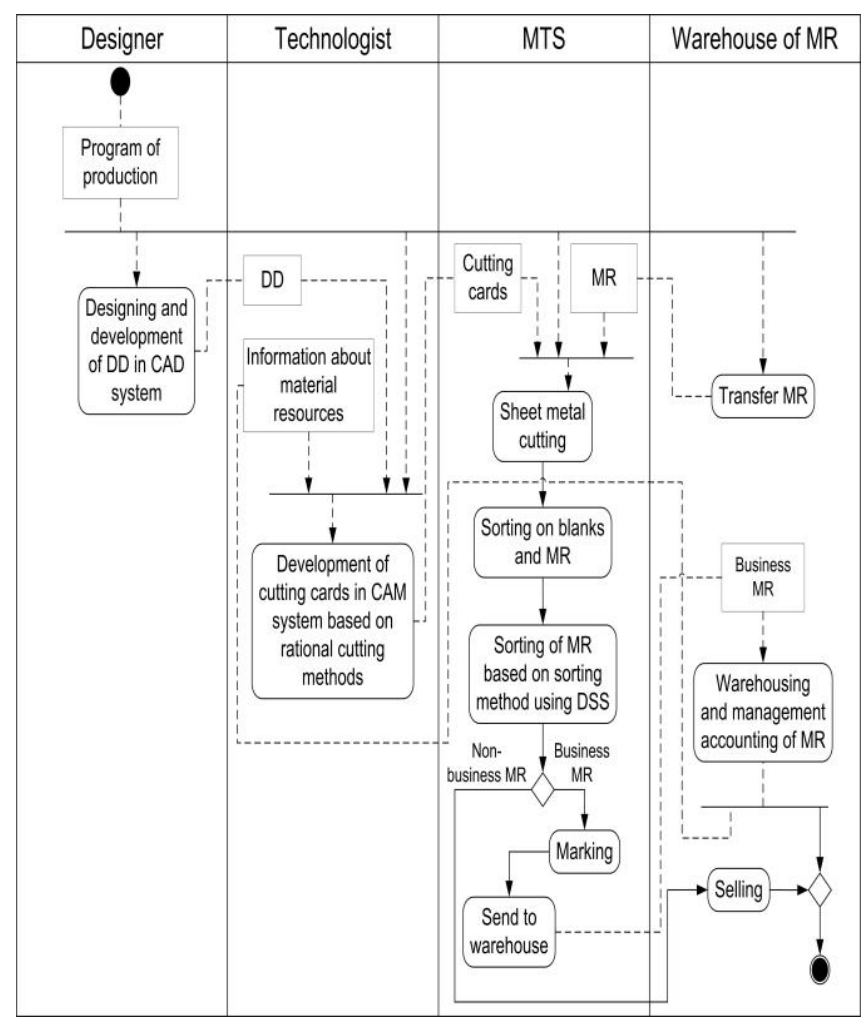

Fig. 1. Process of the sheet metal rational cutting taking into account business MR

An important part of the process is the sorting of sheet metal MR after cutting into business and non-business. For its reasonable implementation, a sorting method has been developed, which consists of determining class of the MR resulting after cutting and sorting it to a group of business or non-business MR based on a comparison a forecasted demand for the MR class in physical terms with MR residues of a similar class at warehouse. Classes of sheet metal are determined in order to keep the necessary accounting and analysis for making sorting decisions. At the same time, it has been proposed to take into account the change of storage and transportation operating costs in forecasting demand for MR class. In order to make operational sorting decisions, the DSS for sorting sheet metal after cutting, which interacts with the ERP system, is being developed together with colleagues.

After sorting, each business MR is marked. It is necessary in order to identify it in further when moving between supply chain participants (blank production warehouse - blank production). It is necessary to account the movement of business MR in the new nomenclature in order to differ the nomenclature of original sheet metal from the business MR in ERP system. That is, it is proposed to obtain a nomenclature of blanks and sheet metal of $n$-th level (business or non-business MR) as a result of the sheet metal cutting. At the same time, additional technological cuts, which are necessary for ensuring of storage and transportation of the MR, will make it possible to form a certain amount of MR after cutting. The sheet metal MR are belonged to certain classes of MR for the purposes of accounting and forecasting of potential demand. The emergence of new nomenclature of business MR in the information system will allow determining the number of 0 - 
th level MR, the cutting was not made from which, and the number of $n$-th level MR. It is valuable for planning the volume of purchases and cutting card designing. Also, for the purpose of inventory analyze and demand forecasting, it is advisable to account sheet metal in two units of measure, in kilograms and pieces.

Also it is advisable to separate the nomenclature of nonbusiness MR in depending on the channels for further selling and significant distinctive characteristics of the MR. For example, when selling non-business MR to organizations that recycle scrap metal, it is advisable to divide the MR into several nomenclatures (for example, «stainless scrap metal», «non-ferrous metal», "other scrap steel metal»), since the selling price depends on the metal grade.

In order to ensure efficient storage of n-th level sheet metal at warehouse, it is advisable to use specialized racks, which are chosen individually depending on the number and size of the received MR.

\section{DISCUSSION}

The formulated conclusions and the obtained results for sheet metal material resources management require further development.

Storing a variety of interchangeable $n$-th level MR makes it necessary to solve the task of determining the sequential actions of a technologist when designing cutting cards taking into account business MR. That is, if the technologist or a rational cutting program choose a specific $n$-th level material resource based on the information stored in the database, then a specialist of blank production have to spend some time searching for the MR specified in the cutting card. Therefore, in the study the variant is considered, when during designing a cutting card the choice of template of material resource class is predetermined, then the bar code of any selected MR from the recommended class is scanned and a specific cutting card is formed. For this, it is important that business MR are stored by the determined classes.

From the point of accounting aspects view, it is necessary to determine the features of forming of the business and nonbusiness MR nomenclature. On the one hand, sheet metal MR obtained after cutting can be considered as semi-finished products, which are produced together with blanks. That is, the sheet metal MR, from which further production is possible, are made as semi-finished products at blank production, and the MR are moved to warehouse. On the other hand, accounting systems allow returning back unused $\mathrm{MR}$ as the original nomenclature to the warehouse, where it can be transformed into the necessary nomenclature by appropriate procedures. At this stage of the study it is suggested that the first variant of accounting is more appropriate from the point of technological process view and for the timely appearing a new nomenclature of sheet metal in the ERP system.

It is necessary to choose a technique for determining the potential demand on sheet metal MR classes. The accumulated information about consumption volume of corresponding class for the previous periods will be the base data for forecasting. Therefore, it is possible to use forecasting methods based on interpolation and extrapolation of statistical data. On the other hand, in single or serial types of production the nomenclature of blanks and sheet metal
MR classes can be often changed when the production program is changed. Also, as it was noted earlier, the change in the costs of storing and transporting of sheet metal MR received after cutting influence economic efficiency of using the MR. Therefore, in these conditions, it is advisable to consider modeling methods, which allow determining the potential demand on MR classes. Together with colleagues from the Vologda State University, the modeling method based on neuro-fuzzy logic is considered, the relevance of which is reflected in the works [16-19], however, the modeling method based on decision trees should also be considered in more detail.

Highlighted aspects should be considered in more detail at the stage of DSS development and improvement of the ERP system. The implementation of the developed proposals using the software will also allow providing operational information about sheet metal MR in the form of various reports (spreadsheets, charts) for managers of enterprise.

It should be noted that, the time taken to master the DSS for sorting sheet metal MR after cutting may differ depending on specifics of operating activities of an engineering enterprise, ERP system and software for rational cutting. Also, it will take time to form statistical information in database of the DSS, on the basis of which the system will gradually begin to offer recommendations for sorting. Therefore, in the research it is necessary to approximately estimate the time and costs of mastering the developed proposals in order to managers of enterprises will can evaluate economic efficiency of the proposals and determine changes in enterprise activity plans. Some of these issues are planned to be decided during approbation of the research results at engineering enterprises of Vologda.

\section{CONCLUSION}

Thus, the following research results obtained in this article:

- The process of sheet metal cutting is described in a general form, taking into account the developed method of sorting sheet metal MR after cutting. This process was considered as micrologistic. It allowed from the point of supply chain management view to identify interacting participants, material and information flows, to correct the internal supply chain of sheet metal MR after cutting, taking into account the developed proposals.

- Research directions of developing tools for material resources management in lean production when sheet metal cutting at engineering enterprises are determined: it is necessary to determine the method for evaluation the potential demand for classes of sheet metal MR; it is important to formulate proposals for organization of the storage and marking sheet metal MR and to define a detailed model of sheet metal cutting business process.

The using of developed proposals based on information technologies at engineering enterprises with single or serial types of production will increase sheet metal utilization rate, reduce unit technological costs, that make it possible to consider variants for optimizing of cost structure or increasing net income of enterprise. 


\section{REFERENCES}

[1] Korolev, I., Ilin, I., Makarov, V., Konnov, G. Importance of CrossSectoral Modeling in Management of Electric Power Sector Based on Green Energy Development Example (2019) Advances in Intelligent Systems and Computing, 983, pp. 306-312.

[2] Ilin, I., Levina, A., \& Iliashenko, O. (2017). Enterprise architecture approach to mining companies engineering. Paper presented at the MATEC Web of Conferences, 106, Article number 08066

[3] D. S. Demidenko and E. D. Malevskaya-Malevich, "Improving production efficiency based on increased using of secondary resources at St. Petersburg enterprises," St. Petersburg State Polytechnical University Journal. Economics, vol. 4, pp. 84-89, 2013.

[4] D. S. Demidenko and E. D. Malevskaya-Malevich, "The economic task of efficient using of industrial waste at enterprise," St. Petersburg State Polytechnical University Journal. Economics, vol. 6, pp. 90-97, 2014.

[5] A. A. Smirnov and A. N. Shichkov, "The organization of sheet metal cutting, taking into account the business material resources at the engineering enterprise," Bulletin of the South Russian Technical University (NPI), vol. 4, pp. 22-35, 2017.

[6] L. V. Kantorovich and V. A. Zalgaller, Rational cutting of industrial materials. Novosibirsk: Science, 1971.

[7] Yu. I. Valiakhmetova and A. S. Filippova, "The L. V. Kantorovich theory of optimal use of resources in cutting-packaging tasks: review and history of the solution methods development.," Bulletin of the Ufa State Aviation Technical University, vol. 1, pp. 186-197, 2014

[8] A. A. Petunin, "Automatic selection of the figure cutting calculation method using a comparative analysis of algorithms," Bulletin of the Tomsk Polytechnic University. Geo Assets Engineering, vol. 5, pp. 169-171, 2010.

[9] V. M. Kartak, M. A. Mesyagutov, E. A. Mukhacheva and A. S. Filippova, "Local search of orthogonal packings using the lower bounds," Automation and Remote Control, vol. 6, pp. 1054-1066, 2009
[10] G. Wascher, H. Haubner and H. Schumann, "An improved typology of cutting and packing problems," European Journal of Operational Research, vol. 3, pp. 1109-1130, 2007.

[11] Bril, A., Kalinina, O., Ilin, I. Small innovative company's valuation within venture capital financing of projects in the construction industry (2017) MATEC Web of Conferences, 106, 08010.

[12] A. N. Shichkov., N. A.Kremlyova and A. A.Borisov, "Designing the operation cycle of a manufacturing and technological system," St. Petersburg State Polytechnical University Journal. Economics, vol. 2, pp. 89-97, 2016.

[13] A. A. Borisov, "Formating of a system of parameters determining the cost of engineering business," Organizer of production, vol. 3, pp. 1922, 2014.

[14] S. B. Suloeva and O. B. Gultceva, "Traditional and modern cost management systems," St. Petersburg State Polytechnical University Journal. Economics, vol. 4, pp. 173-180, 2016.

[15] A. E. Radaev, V. A. Leventsov and V. V. Kobzev, "Optimization models of substantiation of characteristics of a multi-inventory management system at an industrial enterprise," Logistics and supply chain management, vol. 3, pp. 4-20, 2017.

[16] P. V. Skorodumov, "Modelling of economic systems with Petri nets," Economic and Social Changes: Facts, Trends, Forecast, vol. 4, pp. 253-259, 2014.

[17] Rudskoi, A. I., Zolotov, A. M., \& Parshikov, R. A. (2018). Severe plastic deformation influence on engineering plasticity of copper. Materials Physics and Mechanics, 38(1), 64-68.

[18] Rudskoy, A. I., Bogatov, A. A., Nukhov, D. S., \& Tolkushkin, A. O. (2018). New method of severe plastic deformation of metals. Metal Science and Heat Treatment, 60(1-2), 3-6.

[19] A. V. Kroshilin, A. V. Babkin and S. V. Kroshilina, "Features of building decision support systems based on fuzzy logic," St. Petersburg Polytechnical University Journal. Computer Science. Telecommunication and Control Systems, vol. 2, pp. 58-63, 2010. 